\title{
Robust Damping Controller Design in Power Systems with Superconducting Magnetic Energy Storage Devices
}

\author{
Bikash C. Pal, Alun H. Coonick, and Donald C. Macdonald
}

\begin{abstract}
The decentralized design of low-order robust damping controllers is presented based on a weighted and normalized eigenvalue-distance minimization method (WNEDM) employing several superconducting magnetic energy storage (SMES) devices. These controllers are aimed at enhancing the damping of multiple inter-area modes in a large power system. This paper describes a comprehensive and systematic way of designing these controllers. Non-linear simulations further verify the robustness of the damping controllers for various operating conditions.
\end{abstract}

Index Terms-Decentralized control, Hankel singular value (HSV), inter-area oscillation, model reduction, power system damping controller (PSDC), robust stabilization, superconducting magnetic energy storage.

\section{INTRODUCTION}

$\mathbf{I}$ NTER-AREA oscillations [1], [2] are inherent in power systems. The phenomenon is very complex as it involves several electromechanical oscillatory modes associated with several groups of machines distributed over neighboring utilities. These modes are often poorly damped imposing a limit on the maximum power transfer through tie lines. The nature of the interactions in the inter-area modes makes the damping control design task challenging. The design methodology, therefore, should aim at improving the damping performance of one mode while ensuring the least interaction with other modes. In addition, the controller should guarantee stable operation over the full range of system operating conditions. This type of robust control action has been sought by pole-placement [3] and eigenvalue sensitivity [4] based approaches. However, as these methods make use of a single operating condition, the controller obtained may fail under other operating conditions.

Other control techniques such as linear, optimal control (LQG) and $H_{\infty}$ that have been suggested [5], [6] are directed toward providing stable systems with frequency domain objectives such as disturbance rejection and noise attenuation. However, these techniques do not address the objective of closed-loop damping in a straightforward manner. The weighting functions required do not have explicit relationships with the closed-loop damping ratio. In addition, the high-order controllers which are produced are difficult to implement. The

Manuscript received December 28, 1998; revised July 10, 1999.

The authors are with the Department of Electronic and Electrical Engineering, Imperial College, London, SW7-2BT, UK (e-mail; \{b.pal; a.coonick; d.macdonald\}@ic.ac.uk).

Publisher Item Identifier S 0885-8950(00)01890-3.
WNEDM method proposed in [7] is used to design low-order robust damping controllers. The design algorithm is modified to guarantee a stable damping controller for a power system. The design algorithm allows the order of the controller to be chosen-an option that is not available with LQG and $H_{\infty}$ based design techniques.

The use of SMES in power systems was first suggested by Ferrier [8] for load leveling in 1969 . The concept is very simple: a superconducting coil is used to store or release energy by charging or discharging through electronic power converter connected to an ac power system.

The application of SMES to enhance power system damping was first proposed by Peterson [9] followed by others [10]-[12]. In 1983, a 10 MW-30 MJ SMES was commissioned by the Boneville Power Administration (BPA) to damp out low frequency oscillations in the Pacific AC Intertie [13]-[15]. The scope of this paper is restricted to the damping control application of SMES in a power system. Therefore, detail of the benefits, application feasibility studies, cost estimates, technology developments and demonstrations are not described here, but are reported in an overview paper [16]. The option of real power modulation via the SMES is exploited effectively to control power flow oscillations. It is shown in simulations that a controlled sequence of charging and discharging of the SMES coil effectively damps out these oscillations.

\section{STUDY SYSTEM}

The 16-machine and 68-bus system in Fig. 1 is a reduced order representation of the New England and New York interconnected system. The system has five areas as indicated in the diagram. The major links between the NETS and the NYPS are the lines connecting bus \#60-61, \#53-54, and \#53-27. The prefault condition assumes the operation of the system without the line between bus \#60 and \#61. The post-fault system has a line between bus \#53 and \#54 also out of service. The outages of these lines have a significant impact on the damping and frequency of the inter-area modes. The parameters of the network, machines, excitation systems and load generation scenario required for the load flow and stability studies are detailed in [17]. The small signal model of the SMES devices suggested by Rouco et al. [4] is used. The power responses of the SMES devices are assumed to be fast and are modeled by a single time constant. In the steady state, SMES devices do not deliver or absorb real power but their respective reactive power control loop is always closed to provide reactive power support within the 


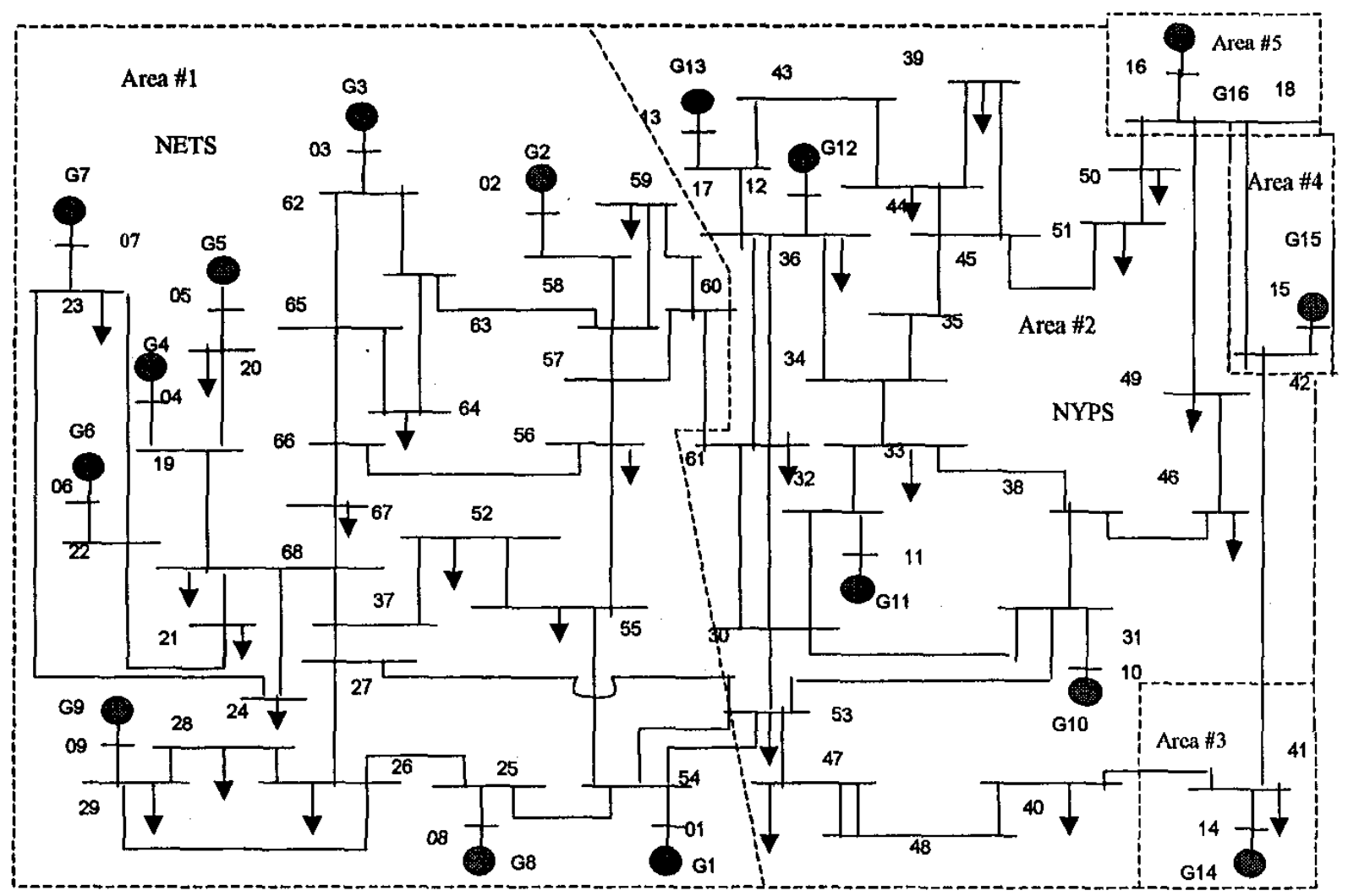

Fig. 1. Sixteen-machine-five-area study system.

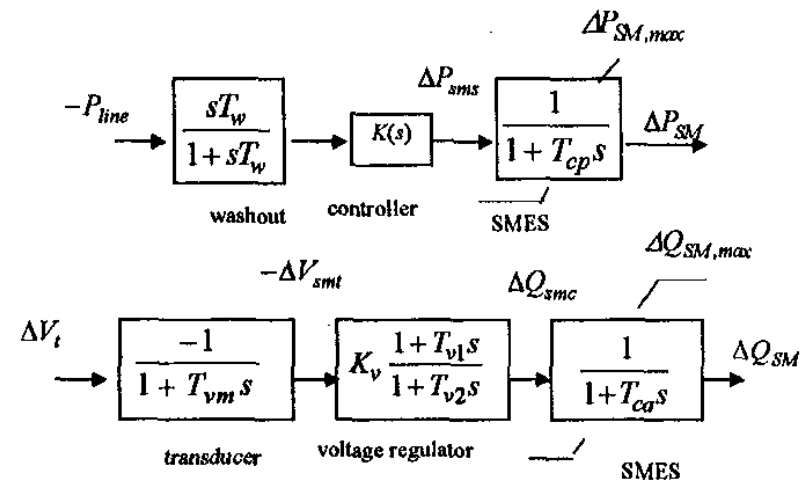

Fig. 2. Small signal model of an SMES unit.

limit. The small signal model is shown in Fig. 2. The detail of the SMES model and its parameters are given in [19].

Eigenvalue analysis of the system shows [17], [18] that the system has four inter-area modes. Their complex values and damping ratios (bracketed terms) are displayed for both operating conditions in Table I. These modes are critical as they are poorly damped. Attention is directed to the design of robust control for these poorly damped modes.

All of the four inter-area modes are not observable in a particular signal nor arc they all controllable from a single bus location. This suggests the installation of more than one SMES.
TABLE I

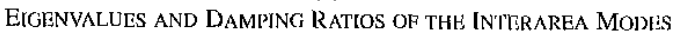

\begin{tabular}{|c|c|c|c|}
\hline $\begin{array}{c}\text { Mode } \\
\text { no. }\end{array}$ & Pre-fault & Post-fault & $\begin{array}{c}\text { Participating } \\
\text { areas }\end{array}$ \\
\hline 1 & $0.140 \pm \mathrm{j} 2.28(0.06)$ & $0.092 \pm \mathrm{j} 2.07(0.04)$ & $1,2 \leftrightarrow 3,4,5$ \\
\hline 2 & $0.122 \pm \mathrm{j} 3.12(0.04)$ & $0.077 \pm \mathrm{j} 3.07(0.02)$ & $1,3,4 \leftrightarrow 2,5$ \\
\hline 3 & $0.129 \pm \mathrm{j} 3.41(0.04)$ & $0.130 \pm \mathrm{j} 3.24(0.04)$ & $1,4,5 \leftrightarrow 2,5$ \\
\hline 4 & $0.248 \pm \mathrm{j} 4.97(0.05)$ & $0.248 \pm \mathrm{j} 4.96(0.05)$ & $1,3,4,5 \leftrightarrow 4$ \\
\hline
\end{tabular}

Four SNES in four different locations arc a natural choice for four modes. The most effective locations and best feedback signats for the SMES units are found by the method of residues [20]. The residue is the product of the modal controllability and modal observability. The modal controllability indicates the degree of influence of the given input to the mode in question. The modal observability is a measure of the modal information contained in a feedback signal. They are independent and hence can be computed separately. The choice of feedback signals is restricted to those locally available, remote signals being less reliable. The selection of the most effective locations and the best feedback signal are made by comparison of the residues at all locations. The comparison amongst residues is only commensurable if the nature of the feedback signals remains the same at all locations. It was found that the active power in the lines had high observability. It is possible to identify a line originating from each bus whose active power provides the maximum residue of 


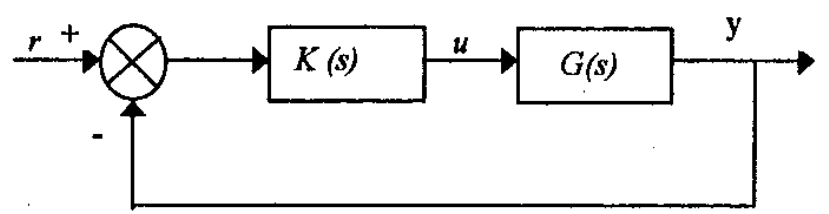

Fig. 3. Closed loop control system.

all the lines originating from the same bus. The most effective location and the best signal combination for a given mode is the one with the highest residue of all possible bus locations. The exercise when carried out for the four modes individually produced bus \#54, \#16, \#13 and \#15 as the best locations with $P_{54,53}, P_{16,18}, P_{13,17}$ and $P_{15,42}$ as the most effective signals to control mode \#1, \#2, \#3 and \#4, respectively. Symbol $P_{54,53}$ means the active power in the line between bus \#54 and \#53. SMES at busses \#54, \#16, \#13 and \#15 are numbered $1-4$, respectively.

\section{CONTROLler DeSIGN PRINCIPLE}

The concept of a low-order robust controller design was developed by Schmitendorf et al. [7]. The method is slightly modified for use in power system damping control design. The method is discussed here briefly.

Consider the single variable feedback configuration of Fig. 3 with $G(s)$ and $K(s)$ as the transfer function of the plant and the controller, respectively. The $G(s)$ and $K(s)$ can be expressed by proper and rational polynomials as:

$$
\begin{aligned}
& G(s)=\frac{N(s)}{D(s)}=\frac{n_{n} s^{n}+n_{n-1} s^{n-1}+\cdots+n_{0}}{d_{n} s^{s}+d_{n-1} s^{n-1}+\cdots+d_{0}} \\
& K(s)=\frac{N_{k}(s)}{D_{k}(s)}=\frac{\tilde{n}_{k} s^{k}+\tilde{n}_{k-1} s^{k-1}+\cdots+\tilde{n}_{0}}{\tilde{d}_{k} s^{k}+\tilde{d}_{k-1} s^{k-1}+\cdots+\tilde{d}_{0}}
\end{aligned}
$$

where $n$ is the order of the plant, $k$ is that of the controller and $d_{n} \neq 0$. A nonzero $d_{n}$ means that $G(s)$ is proper. The transfer function, $T(s)$, of the closed-loop is given by

$$
T(s)=\frac{G(s) K(s)}{1+\bar{G}(s) K(s)}=\frac{N(s) N_{k}(s)}{N(s) N_{k}(s)+D(s) D_{k}(s)}
$$

The characteristic polynomial of 3 can be written as

$$
\delta(s)=N(s) N_{k}(s)+D(s) D_{k}(s) \equiv \delta_{n+k} s^{n+k}+\cdots+\delta_{0}
$$

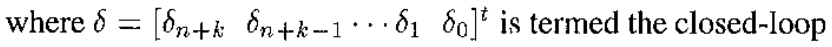
characteristic vector. A similar vector for controller coefficients is defined as:

$$
x=\left[\tilde{n}_{k} \tilde{d}_{k} \tilde{n}_{k-1} \tilde{d}_{k-1} \cdots \tilde{n}_{0} \tilde{d}_{0}\right]^{T^{\prime}} .
$$

The polynomial in (4) can be expressed as a set of algebraic equations when the coefficients of equal power of " $s$ " on both side of (4) are compared. This is given in [21]

$$
P x=\delta
$$

where $P$ is an $(n+k+1) \times(2 k+2)$ matrix with the following structure:

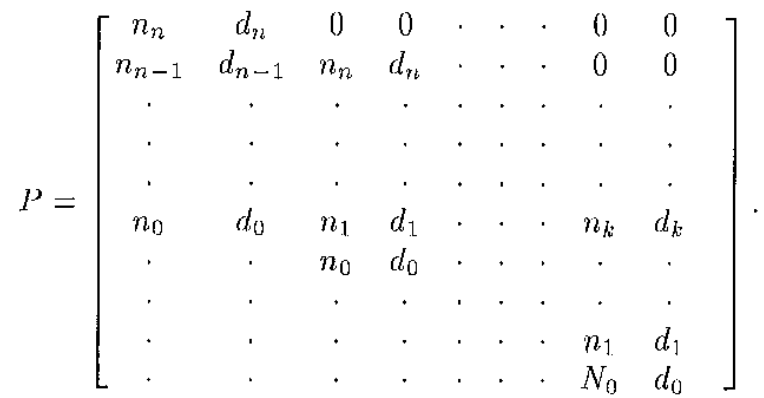

$P$ is called the plant parameter matrix as its elements are obtained from the coefficients of the plant polynomial in (1). Any $\delta$, hence an arbitrary pole-placement, can be achieved by proper choice of $x$ if $P$ satisfies full row rank conditions, i.e., if $k \geq$ $n-1$; so for arbitrary pole-placement the minimum order of the controller is $n-1$. For a plant with a large number of open-loop poles, the order of the controller is very large. It can be reduced if the aim of arbitrary pole-placement of all the closed-loop poles is relaxed to closed-loop stability with special treatment of a few critical poles. This is exactly what is required in power-system-damping-controller design where improved damping ratios of the critical electromechanical modes are of paramount importance and other poles can be ignored so long as they are sufficiently damped. No $x$ will be found to satisfy (6) if a reduced order $(k<n-1)$ controller is sought. The best that can be done is to choose $x$ such that $\left\|P x-\delta^{*}\right\|$ is minimized. This optimization problem approximates the desired characteristic polynomial but the closed-loop poles may not be close to the desired ones. For example, given that two of the desired real poles are -15.0 and -2.0 and the optimization algorithm provide a solution of -12.5 and -0.5 , the absolute error of 1.5 is the same for both poles. But the pole at -0.5 causes a larger change in the dynamics of the system. Instead of minimizing the absolute eigenvalue-distance, it is better to minimize the normalized eigenvalue-distance. Furthermore, the objective of the absolute eigenvalue-distance minimization provides equal treatment of all of the closed-loop eigenvalues. In order to attach more importance to the critical eigenvalues, the objective of eigenvalue-distance minimization must be weighted in addition to normalization. The modified objective function becomes what is shown in (8) at the bottom of the page: where $\left\{\mu_{i}\right\}$ and $\left\{\lambda_{i}\right\}$ are the desired and the actual closed-loop poles respectively and $c_{i}$ is the weight associated with the $i$ th pole.

$$
F^{\prime}(x)=\sum_{i=1}^{n+k} C_{i} \frac{\left\|\mu_{i}-\lambda_{i}(x)\right\|}{\left\|\mu_{i}\right\|}=\sum_{i+1}^{n+k} \frac{C_{i}}{\left\|\mu_{i}\right\|} \sqrt{\left(\left[\operatorname{Re}\left(\mu_{i}\right)-\operatorname{Re}\left(\lambda_{i}(x)\right)\right]^{2}+\left[\operatorname{Im}\left(\mu_{i}\right)-\operatorname{Im}\left(\lambda_{i}(x)\right)\right]^{2}\right)}
$$


The controller parameter vector $x$ is optimized based on the plant parameter matrix $P$. As the operating condition varies, so does $P$. In order to maintain acceptable performance in other operating conditions, the robustness property has to be built into the controller. This will be achieved by extending the technique already described to incorporate other plant parameter matrices corresponding to several (say $q$ ) operating conditions. For a specific choice of 5 and an initial choice of $x, q$ weighted and normalized eigenvalue-distances are evaluated. The objective of the optimization procedure is to find $x$ such that the maximum of all of the objectives $\left\{F_{j}(x)\right\}$ is minimized. This is a typical unconstrained optimization problem as there is no bound on $x$. It may produce an $x$ to provide the desired closed-loop damping. But the controller can have unstable poles and right-half-plane zeros. This drawback is overcome by the introduction of a constraint to ensure a stable and minimum phase controller. The controller design task reduces to a constrained nonlinear optimization problem as:

$$
\begin{gathered}
\text { Minimize } \underset{x}{\operatorname{maximize}} F_{j}(x) \\
\text { subject to: } \operatorname{Real}\left(\operatorname{roots}\left(N_{k}(s), D_{k}(s)\right)\right)<0 .
\end{gathered}
$$

This typical constraint min-max problem is solved by a nonlinear optimization technique such as Sequential Quadratic Programming (SQP) [22]. A least-square solution of (6) provides the initial value of $x$.

The technique described above is applied to the damping controller design for the study system. The controllers are designed sequentially, i.e., once a controller is designed it is treated as an integral part of the system for which the subsequent controllers are designed. The open-loop system has 145 states, including 12 states associated with three SMES devices. The transfer function between $\Delta P_{54,53}$ and real power input $\Delta P_{s m s}$ of SMES $\# 1$ is considered first. For a second order controller, die number of closed-loop poles to be specified is 147 , which is neither practical nor necessary. To ease the controller design, the order of the plant is reduced to a much lower order by model reduction. The optimal Hankel norm approximation [23] available with the robust control toolbox in Matlab [24] is used to obtain a 10th order reduced plant The order of the reduced plant is immaterial as long as the input-output characteristic in die desired frequency range is very close to that of the full system. In order to justify this, the frequency response of the full plant and the reduced plant is shown in Fig. 4.

Fig. 4 shows that the reduced plant closely approximates the input-output characteristic of the full plant in the desired frequency range.

The specified poles can be obtained by designing a second order controller for the reduced order plant in the prefault case by a conventional method such as the root-locus technique. The closed-loop poles then can be set as the specified poles $[\{\mu\}$ in (8)]. These pole locations obtained by the root-locus method provide adequate damping in the prefault case but fail to do so post-fault. The algorithm formulates $\{P\}$ for both operating cases and looks for a controller that provides adequate damping in both operating cases. A converged solution is acceptable if the damping ratio for the inter-area mode in question is between
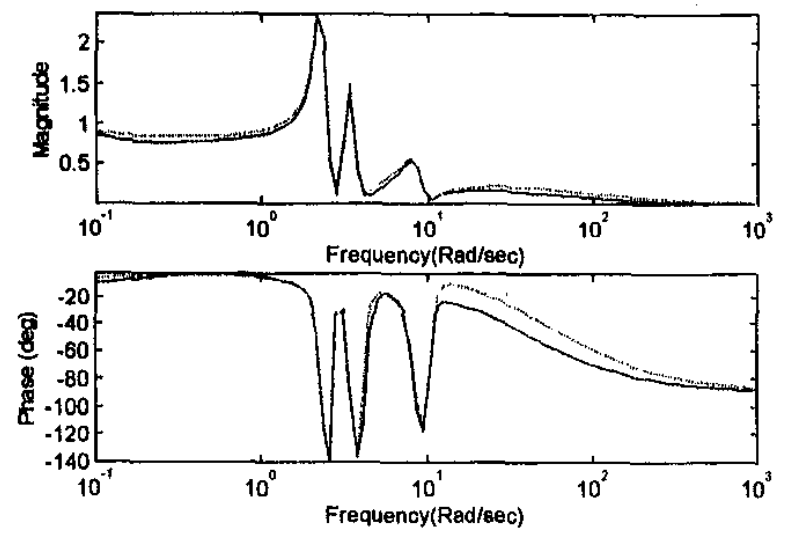

Fig. 4. Frequency response of the plant. Solid line: full order plant and dotted line: reduced order plant.

TABLE II

CRITICAL POLES OF THE RidUChD PLANT

\begin{tabular}{|c|c|c|}
\hline Open-loop poles & $\begin{array}{c}\text { Specified closed- } \\
\text { loop poles }\end{array}$ & $\begin{array}{c}\text { Actual closed-loop } \\
\text { poles }\end{array}$ \\
\hline$-0.75 \pm j 8.39$ & $-1.09 \pm j 9.15$ & $-1.08 \pm \mathrm{j} 9.15$ \\
\hline$-0.14 \pm j 3.41$ & $-0.43 \pm j 3.52$ & $-0.43 \pm \mathrm{j} 3.52$ \\
\hline$-0.05 \pm j 3.11$ & $-0.07 \pm \mathrm{j} 3.11$ & $-0.07 \pm \mathrm{j} .11$ \\
\hline$-0.14 \pm \mathbf{2 . 2 9}$ & $-0.36 \pm \mathbf{2 . 5 5}$ & $-0.35 \pm \mathbf{2 . 5 5}$ \\
\hline
\end{tabular}

0.15 and 0.20 in both operating cases. Table II lists the critical open-loop poles and the specified poles for the reduced plant. The poles in the last row are equivalent of mode \#1 in the reduced order system. The plant parameter matrices are formed from the reduced order plants in both operating cases. The "minimax" routine available in the optimization toolbox [25] with Matlab is used to find the parameters of the controller. The weights are selected as 100 for those real poles with very small decay rates and $50 * \rho_{\min } / \rho$ for the poles with very poor damping ratios. Here, $\rho_{\min }$ is the minimum desired damping ratio and $\rho$ is the damping ratio calculated in every iterative step toward the convergence. The choice of weights is based on the suggestions made in [7]. Slight changes in weights do not seem to affect the stability of the convergence. The critical poles obtained from this optimization are listed in Table II. The transfer function of the second order controller constructed from $x$ ensuring adequate damping of the highlighted mode is given by

$$
K_{1}(s)=2086.8 \frac{s+0.0163}{s^{2}+422.83 s+5004} .
$$

The transfer function of the real power block of SNES \#2 is evaluated with $K_{1}(s)$ connected to the full system. The model reduction is performed and the controller design procedure is repeated with another specified set of closed-loop poles to obtain the second order controller given by:

$$
K_{2}(s)=14.433 \frac{s^{2}+2.0714 s+0.111}{s^{2}+54.16 s+53.26} .
$$

The model reduction and the $P$ matrix formulation etc. is repeated to design the damping controller for SMES \#3 to improve the damping of mode $\# 3$. The controller is given as:

$$
K_{3}(s)=0.80276 \frac{s^{2}+177560 s+3.2755}{s^{2}+30329 s+523550} .
$$


TABLE III

EITECT OF AlL DAMPMNG CONTROLI.FRS ON THF INTERAREA MODES

\begin{tabular}{|c|c|c|c|c|c|c|c|c|}
\hline \multirow{3}{*}{$\begin{array}{l}\text { Mode } \\
\text { no. }\end{array}$} & \multicolumn{4}{|c|}{ Pre-fault } & \multicolumn{4}{|c|}{ Post-fault } \\
\hline & \multicolumn{2}{|c|}{$\begin{array}{l}\text { With SMES } \\
\text { and no } \\
\text { controller }\end{array}$} & \multicolumn{2}{|c|}{$\begin{array}{l}\text { With SMES } \\
\text { and with all } \\
\text { controllers }\end{array}$} & \multicolumn{2}{|c|}{$\begin{array}{l}\text { With SMES } \\
\text { and no } \\
\text { controller }\end{array}$} & \multicolumn{2}{|c|}{$\begin{array}{l}\text { With SMES } \\
\text { and with all } \\
\text { controllers }\end{array}$} \\
\hline & 5 & $f(\mathrm{~Hz})$ & 5 & $f(\mathrm{~Hz})$ & $s$ & $f(\mathrm{~Hz})$ & $c$ & $f(\mathrm{~Hz})$ \\
\hline$\# 1$ & 0.06 & 0.36 & 0.21 & 0.39 & 0.04 & 0.33 & 0.20 & 0.35 \\
\hline$\# 2$ & 0.04 & 0,49 & 0.21 & 0.54 & 0,02 & 0.48 & 0.19 & 0.53 \\
\hline$\# 3$ & 0.04 & 0.54 & 0.22 & 0.67 & 0,04 & 0.51 & 0.25 & 0.63 \\
\hline$\# 4$ & $\overline{0.05}$ & 0.79 & 0.11 & 0.78 & 0.05 & 0.79 & 0.11 & 0.78 \\
\hline
\end{tabular}

Eigenvalue analysis is performed with the three controllers connected to the system. Each controller has a washout filter of $10 \mathrm{~ms}$ time constant to prevent it from responding to gradual changes in line power.

\section{Performance Evaluation}

Table IIJ lists the damping ratios and frequencies of the critical modes. It is clear that the damping ratios of all four modes have been improved to a satisfactory level in both operating conditions. It is also interesting to see that the damping of mode \#4 is improved by these controllers and hence, eliminating the need for the fourth SMES. The effect of each of the controllers on the damping of the overall system is examined. The effect of $K_{1}(s)$ is examined by disconnecting $K_{2}(s)$ and $K_{3}(s)$ from the system. It was found that the damping of mode \#1 was improved primarily by $K_{1}(s)$ with a slight improvement of damping of mode \#3 in the prefault case. The damping of other modes remains unaffected. Similarly $K_{2}(s)$ is found to improve the damping of mode \#2 very satisfactorily. It also improves the damping of mode \#4 significantly, $K_{3}(s)$ improves the damping of mode \#3 primarily with a significant contribution to the damping of mode \#4. The joint action of $K_{2}(s)$ and $K_{3}(s)$ improves the damping of mode \#4 to a satisfactory value. The performance of the controllers has also been evaluated for other load characteristics. Initially, the design was made with a constant-impedance load. Damping ratios were also computed for constant-current (CC), constant-power (CP) and an equal mix of $\mathrm{CC}$ and $\mathrm{CP}$. They were found to be highly satisfactory. The detail results of individual controller performance and loads characteristics can be found in [19].

In order to verify the performance of the controller in the face of system nonlinearity and saturation, a nonlinear simulation was performed. A 3-phase fault at bus \#53 is assumed for $70 \mathrm{~ms}$ in one of the tie lines between bus \#53 and bus \#54. The fault is cleared by the removal of the faulted circuit. The simulation is performed for $20 \mathrm{~s}$. An output limit of $\pm 10 \mathrm{MW}$ is set for each SMES. The variations of machine angles with reference to machine \#15 are computed. The relative angular variation of one machine from each group is plotted for the last $15 \mathrm{~s}$ of the simulation interval. Also plotted in Fig. 5 is the real power flow in the line between bus \#53 and bus \#54 and the real power output responses of the SMES. It can be seen that the oscillations settle down in 10-15 $\mathrm{s}$ and there are no adverse interactions of controller modes, exciter modes and electromechanical modes (both local and inter-area).

The sizing of the SMES device requires the evaluation of both power and energy ratings. Fig. 5 shows that the real power
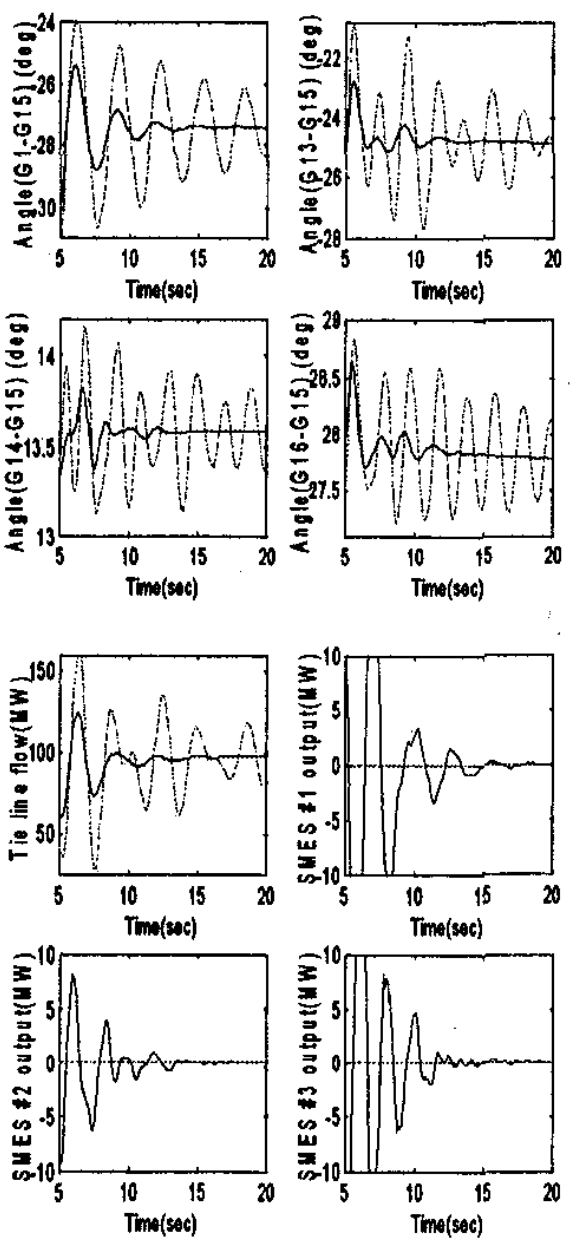

Fig. 5. Dynamic responce of the system following a 3-ph fault at bus $\# 53$. Solid line: with controllers and dotted line: without controllers.

outputs of the SMES oscillate between $\pm 10 \mathrm{MW}$ limits for the first 3-8 $s$ after the fault is applied and following this, the SMES real power outputs quickly settle to zero. The absolute value of the largest individual area (charging or discharging) is the energy rating in MJ when power is expressed in MW. The detail of the method of sizing calculation is described in [17] and [19]. It was found that $10.5,6.49$ and $10.61 \mathrm{MJ}$ were the required rating of the SMES \#1, \#2 and \#3 respectively. Recent technology developments and demonstrations [18] for micro SMES $(1-10 \mathrm{MJ})$ in the USA under the initiatives of the Department of Energy (DOE), defense establishments and various other industrial houses make one feel that a 10 MJ SNES coil will be commercially available in the near future.

\section{CONCLUSIONS}

An effective method of low-order robust control design is applied successfully in a large power system that suffers from very lightly damped inter-area oscillations. The method of controller design is very general. It can be applied to power system damping control design employing other FACTS devices.

The performance evaluations in the frequency and time domains show that the coordinated actions of three small SMES 
each of 10-MW power rating for $1 \mathrm{~s}$ with a damping controller are necessary to maintain robust damping of the system in both operating cases.

The controllers do not interact adversely with local modes or exciter modes. This observation has also been made for two other study systems. However, detailed study is needed including other FACTS devices, before this aspect can be generalized.

The performance of the controllers is largely insensitive of load characteristics.

\section{REFERENCES}

[1] "Analysis and control of power system oscillation," CIGRE, Special Publication 38.01.07, Technical Brochure 111, 1996.

[2] P. Kundur, Power System Stability and Control, USA: McGraw Hill, 1994.

[3] P. Kundur, M. Klein, G. J. Rogers, and M. S. Zywno, "Application of power system stabiliser for enhancement of overall system stability," IEEE Trans. on Power Systems, vol. PWRS-4, pp. 614-626, May 1989.

[4] L. Rouco, F. L. Pagola, A. Garcia-Cerrada, J. M. Rodriguez, and R. M. Sanz, "Damping of electromechanical oscillations in power systems with superconducting magnetic energy storage systems-location and controller design," in Proc. of 12 th Power System Computation Conference, Dresden, Aug. 19-23, 1996, pp. 1097-1 104.

[5] C. S. Jang, T. H. Kim, J. K. Past, and S. I. Moon, "An L. ? based PSS design for controlling the SSR in power systems with seric. compensated lines," IEEE Truns. on Energy Conversion, vol. 11, no. 2, pp. 423-428, 1996.

[6] M. Klein, L. X. Lee, G. J. Rogers, S. Fatrokhpay, and N. J. Balu, " $l_{\infty}$ damping controller design in large power systems," Trans. on Power Systems, vol, PWRS-10, no. 1, pp. 159-166, Feb. 1995.

[7] W. E. Schmitendorf and C. Wilmers, "Simultaneous stabilization via low order controllers," in Control and Dynamic Systems. San Diego, CA: Academic Press Inc., 1991, vol. 35, pp. 165-184.

[8] M. Ferrier, "Stockage d'energic dans un enroulement supraconducteur," Journal of the International Institute of Refrigeration, Low Temperature and Electric Power, p. 150, 1969.

[9] H. A. Peterson, N. Mohan, and R. W. Boom, "Superconductive energy storage inductor-converter units for power systems," IEEE Trans. on Power Apparatus and Systems, vol. PAS 94, no. 4, pp. 1337-1349, 1975.

[10] Y. L. Tan and Y. Wang, "Augmentation of transient stability using a superconducting coil and adaptive nonlinear control," IEEE Trans. on Power Systems, vol, 13, no. 2, pp. 361-366, 1998

[11] Y. Mitani, K. Tsuji, and Y. Murakami, "Application of SMES to improve power system dynamic performance," IEEE Trans, on Power Systerns, vol. 3, no, 4, pp. 1419-1425, 1989.

[12] J. B. Simo and I. Kamwa, "Exploratory assesment of the dynamic behavior of multimachine stabilized by a SMES unit," Trans. on Power Systems, vol, 10, no. 3, pp. 1566-1571, Aug. 1995.

[13] R. I. Schermer, H. J. Boeing, and J. Dean, " 30 MJ superconducting magnetic energy storage for BPA transmission line stabiliser," IEEE Trans. on Magnetics, vol. Mag-17, no. 5, pp. 1950-1953, Sept. 1981.
[14] J. D. Rogers, R. I. Schermer, B. L. Miller, and J. F. Hauer, "30 MJ superconducting magnetic energy storage system for utility transmission line stabitization," Proc. of the IEEE, vol. 71, no. 9, pp. 1099-1 107, Sept. 1983.

[15] J. F. Hauer and H. J. Boeing, "Control aspects of the Tacoma superconducting magnetic energy storage project," IEEE Trans, on Power Systems, vol, 2, no. 2, pp. 443-450, May 1987.

[16] C. A. Luongo, "Superconductiing storage systems: An overview," Trans. on Magnetics, vol. 32, no, 4, pp. 2214-2223, July 1996

[17] B. C. Pal, "Robust damping control of inter-area oscillations in power systems with superconducting magnetic energy storage devices," Ph.D dissertation, University of London, 1999.

[18] G. Rogers, "Power system structure and oscillations," IEEE Computer Applications in Power, vol. 12, no. 2, pp. 14-21, Apr. 1999.

[19] B. C. Pal, A. H. Coonick, I. M. Jaimoukha, and H. EI-Zobaidi, "A linear matrix inequality approach to robust damping control design in power systems with superconducting magnetic energy storage device,", PE-439-PWRS-0-01-1999.

[20] N. Martin and L. T. G. Uma, "Determination of suitable locations for power system stabilizer and static var compensators for damping electromechanical oscillations in large power systems," IEEE Trans. on Power Systems, vol. 5, no. 4, pp. 1455-1469, Nov. 1990.

[21] C. T. Chen, Linear System Theory and Design. Now York: Holt, Rinehart and Winston, 1984.

[22] R. K. Brayton, S. W. Director, G. D. Hatchel, and L. Vidigal, "A new algorithm for statistical circuit design based on quasi Newton methods and function splitting," IEEE Trans. on Circuit and Systems, vol. CAS-26, pp. 784-794, Sept. 1979

[23] S. Skogestad and I. Postlethwaitc, Multivariable Feedhack Control Analysis and Design: John Wiley and Sons, 1996.

[24] R. Y. Chiang and M. G. Sofonov, Robust Control Toolbar for Use with Matlab: The Math Works Inc., 1996.

[25] M. A. Branch and A. Grace, Optimization Toolbox for Use with Matlab: The Math Works Inc., 1996.

Bikash C. Pal received his B.E.E. (Hons.) and M.E. degrees from Jadavpur University and the Indian Institute of Science in 1990 and 1992 respectively. Between 1992 and 1996 he worked with Tata Consulting Engineers, India and Jadavpar University, India. Currently, he is with Imperial College as a Ph.D. student.

Nlun H. Coonick graduated from the University of Southampton in 1980 and obtained his Ph.D. degree in 1991. He is a Lecturer in the Department of Electronic and Flectrical Enginecring. Imperial Colloge. His research interest includes power system stability and control, using FACTS devices, and artificial intelligence applied to power systems.

Donald C. Macdonald graduated from Imperial College in 1956 and obtained his $\mathrm{Ph} . \mathrm{D}$. degree in 1969. He has a long-term interest in machine parameters and system control. He has been with Imperial College since 1964. 